\section{Response to: 'Physician global assessment in systemic lupus erythematosus: can we rely on its reliability?' by Chessa et al}

We thank Chessa et al for their interest in our article on lupus Physician's Global Assessment (PGA). ${ }^{1}$ Their correspondence discusses the measurement used to determine PGA scoring reliability and suggests that the intraclass correlation coefficient (ICC) used, ICC2,k, with a two-way random effect model based on mean scorings may have increased the reliability estimates reported, compared with a two-way random effect models based on individual data points (ICC2,1). ${ }^{2}$ Indeed correlation coefficients were approximately $39 \%$ lower for the pre-lab PGA and 27\% lower for the post-labPGA when computed with the ICC2,1 compared with the ICC2,k. We used the ICC2,k to assess inter-rater reliability as our study was designed to evaluate and compare mean PGA scores before and after receipt of laboratory values from multiple $(\mathrm{k}=50)$ raters. $^{3}$ Additionally, mean-based models $(\mathrm{ICC} 2, \mathrm{k})$ are conventionally used to report ICC. Which of these models is more mathematically or conceptually correct remains debated. Importantly, both models showed increased agreement when laboratory values are available (post-lab PGA) compared with the pre-lab PGA. We wholeheartedly agree that further standardisation and precise guidelines for its scoring will likely improve the performance of the PGA when used by lupus experts and practising rheumatologists.

\section{Anca Askanase, ${ }^{1}$ Shereen Oon $\odot_{1}{ }^{2}$ Molla Huq, ${ }^{3}$ Alicia Calderone, ${ }^{2}$} Eric F Morand $\odot,{ }^{4}$ Mandana Nikpour, ${ }^{5}$ Cynthia Aranow $\odot^{6}$

${ }^{1}$ Rheumatology, Columbia University College of Physicians and Surgeons, New York, New York, USA

${ }^{2}$ Rheumatology, St Vincent's Hospital, Fitzroy, Victoria, Australia

${ }^{3}$ Department of Medicine, University of Melbourne, Melbourne, Victoria, Australia

${ }^{4}$ School of Clinical Sciences, Monash University, Clayton, Victoria, Australia

${ }^{5}$ Department of Medicine, University of Melbourne, Fitzroy, Victoria, Australia

${ }^{6}$ The Feinstein Institute for Medical Research, Manhasset, New York, USA
Correspondence to Dr Cynthia Aranow, The Feinstein Institute for Medical Research, Manhasset, NY 11030, USA; caranow@northwell.edu

Handling editor Josef S Smolen

Contributors All authors contributed to this correspondence response.

Funding The authors have not declared a specific grant for this research from any funding agency in the public, commercial or not-for-profit sectors.

Competing interests None declared.

Patient and public involvement Patients and/or the public were not involved in the design, or conduct, or reporting, or dissemination plans of this research.

Patient consent for publication Not required.

Provenance and peer review Commissioned; internally peer reviewed.

(c) Author(s) (or their employer(s)) 2020. No commercial re-use. See rights and permissions. Published by BMJ.

\section{Check for updates}

To cite Askanase A, Oon S, Huq M, et al. Ann Rheum Dis Epub ahead of print: [please include Day Month Year]. doi:10.1136/annrheumdis-2020-217692

Received 5 May 2020

Accepted 5 May 2020

\section{Linked}

- http://dx.doi.org/10.1136/annrheumdis-2020-217632

Ann Rheum Dis 2020;0:1. doi:10.1136/annrheumdis-2020-217692

\section{ORCID iDs}

Shereen Oon http://orcid.org/0000-0002-6822-5711

Eric F Morand http://orcid.org/0000-0002-9507-3338

Cynthia Aranow http://orcid.org/0000-0001-9299-0053

\section{REFERENCES}

1 Aranow C, Askanase A, Oon S, et al. Laboratory investigation results influence physician's global assessment (PGA) of disease activity in SLE. Ann Rheum Dis 2020:pii: annrheumdis-2019-216753.

2 Chessa E, Piga M, Arnaud L. Physician global assessment in systemic lupus erythematosus: can we rely on its reliability? Ann Rheum Dis accepted 2020.

3 Koo TK, Li MY. A guideline of selecting and reporting intraclass correlation coefficients for reliability research. J Chiropr Med 2016;15:155-63. 